\title{
Variability in Instruction of Introductory Chemical Engineering Course: Does it affect our students?
}

\section{Elif Miskioglu, The Ohio State University}

Elif Miskioglu graduated from Iowa State with a B.S. in Chemical Engineering and minor in Genetics. She is currently a PhD candidate at The Ohio State University, where she is studying learning styles in the chemical engineering undergraduate student population. 


\section{Variability in Instruction of Introductory Chemical Engineering Course: Does it Affect Our Students?}

Abstract

Engineers are commonly described as problem solvers. Arguably, the best problem solvers consist of the most versatile information-gatherers and processors. Learning styles describe how individuals gather and process information. The Felder-Silverman learning styles model consists of eight learning styles dimensions, with two opposing preferences in each dimension (active/reflective, sensing/intuitive, visual/verbal, sequential/global) that categorize individuals based on how they best process, perceive, receive, and understand information. It is important to note that these descriptions of learning styles are preferences, and not absolute characteristics, and the Felder-Silverman model accounts for "balanced," "moderate," and "strong" preferences within each dimension. However, because learning styles describe the cognitive processes involved in problem solving, it may be argued that individuals with more balanced learning styles will be better problem solvers. Originally, our study focused on the correlation between student learning styles, problem solving strategies, self-efficacy, attitudes/perceptions, and performance in an introductory undergraduate chemical engineering course at a large Midwestern university, in an effort to better understand our student population and provide a basis for curricular development. We were interested in understanding whether there were observable differences in student performance and self-efficacy that correlated with student learning style, specifically on problems that exhibited a learning style bias in presentation or solution. We categorized the learning styles engaged by exam problems in their presentation and their solution and ran statistical analyses for correlation with performance and self-efficacy. While we discovered several instances where students of one learning style preference outperformed or underperformed compared to students of another learning style preference on specific problems, we made an even more interesting observation in categorizing the learning styles exploited by exam problems of different instructors. The study has been conducted in two separate sections of the same course, offered the same semester, by different instructors. There was a large observable difference in the learning styles utilized in exam problems by instructor. Some concepts and equations used were the same, but the ways in which students were asked to process and problem solve were drastically different. One section had exams that contained only a few problems, each of a highly sequential and numeric nature. Intuitive problems were nearly non-existent. The other section's exams had five or six questions, and nearly each question utilized multiple learning styles in presentation and solution methods. We are currently repeating the study with two more sections of the same course, again with two separate instructors, and observations are similar (results not available at time of this submission, but will be available by June 2015). We are adding an end-of-term general chemical engineering self-efficacy and concept inventory in an attempt to better understand whether the courses may be considered equivalent despite these observable differences in teaching style. We believe these differences in student experience may show significant impact on student understanding of the introductory course material, as well as correlate with self-efficacy and future outcomes. After multiple semesters of evaluation are complete, we will propose a new course model that ensures a more consistent experience in this course, and hopefully a better foundation for all students in the material. 


\section{Motivation}

Our interest in studying the introductory course in chemical engineering, commonly referred to as material balances (mass and energy balances), stemmed from repeated faculty comments regarding poor student performance. Exams were being designed in a way that the faculty believed the class should have an approximately $80 \%$ average grade, but the actual class results were often at or below $50 \%$. As the first course in our program, we place a high value on positive student outcomes in material balances and ensuring our students receive a strong foundation for the subsequent coursework in chemical engineering. Seeing a potential area for course improvement and curriculum development, we became curious in evaluating student factors for success in the course. We wanted to better understand student performance, perception, and problem solving approaches. Since learning styles describe how individuals receive, perceive, process, and understand information, we began our investigation into student factors for success through the lens of learning styles.

\section{Background}

There are more than 71 models of learning styles in the literature, each with a varying structure. ${ }^{1,2}$ For several reasons, we have chosen to use the Felder-Silverman model. The FelderSilverman model is multidimensional; it contains four dimensions with two opposing preferences in each dimension that describe learning styles. ${ }^{3}$ This generates 16 possible individual learning styles profiles $\left(2^{4}\right)$ in contrast to the four learning styles of the popular Kolb model. ${ }^{4}$ Furthermore, the Felder-Silverman model accounts for strength of preference within a dimension, categorizing individuals as having a "strong" or "moderate" preference, or as balanced in the dimension. ${ }^{3,5}$ This allows for greater sensitivity in assessing learning style preferences, and provides a tool with which we can more closely examine whether specific components (dimensions) of learning style preferences have stronger correlations with student performance. Additionally, while the Felder-Silverman model has been used in fields ranging from computer science to internal medicine, ${ }^{5-7}$ it was originally developed as a learning styles model for engineering specifically. ${ }^{3}$

The four dimensions of the Felder-Silverman model are active/reflective, sensing/intuitive, visual/verbal, and sequential/global. ${ }^{3}$ These dimensions describe how individuals process, perceive, receive, and understand information, respectively. ${ }^{3}$ The preferences are further described in Table 1. Along with the learning styles model, Felder and Silverman developed a corresponding model for teaching styles that may be used to address each learning style. ${ }^{3} \mathrm{~A}$ summary of the teaching styles and associated learning styles is depicted in Figure 1. 
Table 1. Description of dimensions and learning styles preferences of the Felder-Silverman model.

\begin{tabular}{|c|c|c|}
\hline $\begin{array}{c}\text { Learning } \\
\text { Dimension }\end{array}$ & Preference & Description (preference for...) \\
\hline \multirow{2}{*}{ Processing } & Active & Trying things out to learn new material \\
\cline { 2 - 3 } & Reflective & Thinking about new material before trying something \\
\hline \multirow{2}{*}{ Perceiving } & Sensing & Concrete, numerical, factual information \\
\cline { 2 - 3 } & Intuitive & Abstract, conceptual, theoretical information \\
\hline \multirow{2}{*}{ Receiving } & Visual & Graphs, diagrams, pictures, and other visuals \\
\cline { 2 - 3 } & Verbal & Words, spoken or written \\
\hline \multirow{2}{*}{ Understanding } & Sequential & Linear thought process \\
\cline { 2 - 3 } & Global & Non-linear, may jump around and learn in "fits and starts" \\
\hline
\end{tabular}
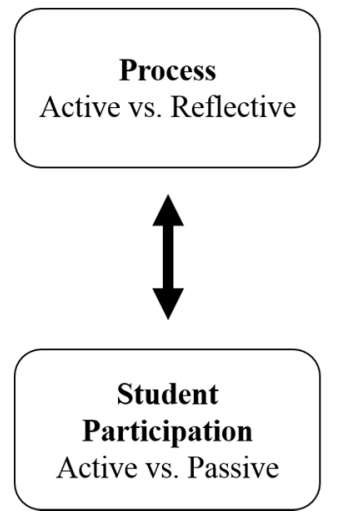
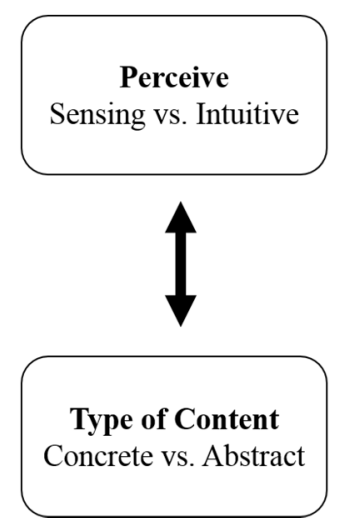
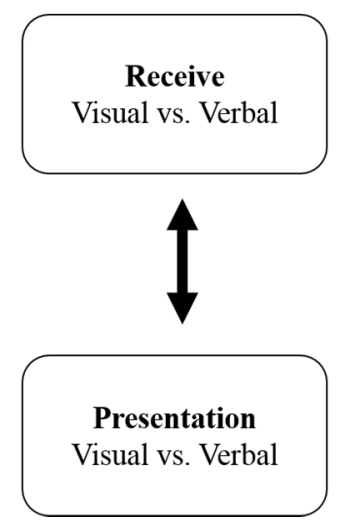

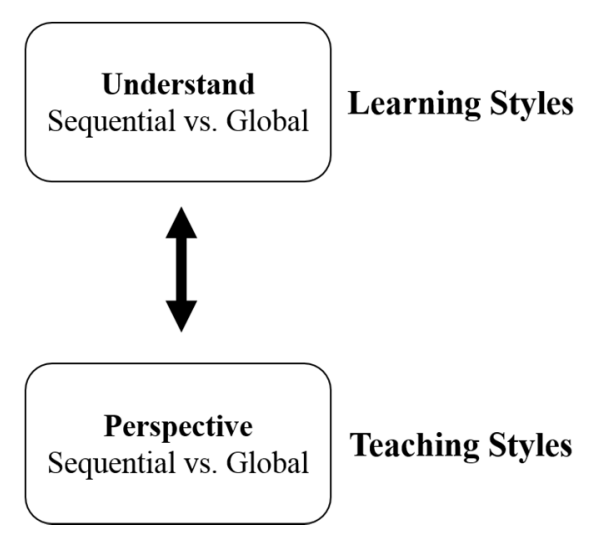

Figure 1. Summary of learning styles and associated teaching styles.

In order to evaluate individual learning style preferences in the Felder-Silverman model, Felder and Soloman developed the Index of Learning Styles Questionnaire (ILS). ${ }^{5}$ This is a 44-question survey consisting of 11 dichotomous, forced choice, questions for each of the four dimensions of the Felder-Silverman model. ${ }^{5}$ The ILS is scored by arbitrarily assigning a +1 score to answers of one preference within a dimension, and a -1 for answers of the opposite preference.

Conventionally, active, sensing, visual, and sequential are assigned the positive value. Since there are 11 questions per dimension, the final score is a positive or negative odd integer between 1 and 11. A score of 1 or 3 is considered "balanced" within a dimension, 5 or 7 a "moderate" preference, and 9 or 11 a "strong" preference..$^{5}$ The sign of the score reveals which preference is dominant, however, the score is reported as an absolute value on a scale as depicted in Figure 2. The ILS has shown good results in studies on reliability and validity. ${ }^{5,8,9}$ The ILS is publicly available through North Carolina State University. ${ }^{10}$ 


\begin{tabular}{|c|c|c|c|c|c|c|c|c|c|c|c|}
\hline \multirow[t]{3}{*}{ Active } & & & & & $\mathrm{x}$ & & & & & & Reflective \\
\hline & 9 & 7 & 5 & 3 & 1 & 1 & 3 & 5 & 7 & 9 & 11 \\
\hline & & & & & $\leftarrow$ & $\rightarrow$ & & & & & \\
\hline
\end{tabular}

\begin{tabular}{|c|c|c|c|c|c|c|c|c|c|c|c|}
\hline \multirow[t]{3}{*}{ Sensing } & & & & & & & & & $x$ & & Intuitive \\
\hline & 9 & 7 & 5 & 3 & 1 & 1 & 3 & 5 & 7 & 9 & 11 \\
\hline & & & & & $\leftarrow$ & $\rightarrow$ & & & & & \\
\hline
\end{tabular}

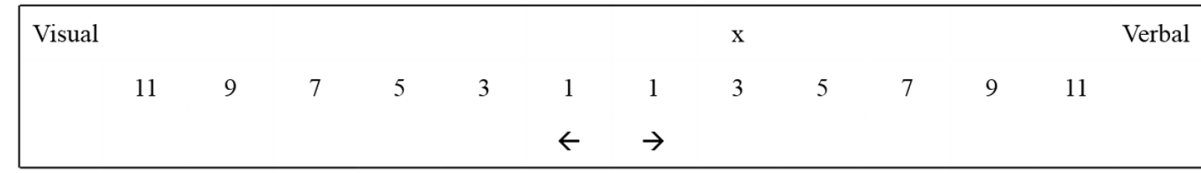

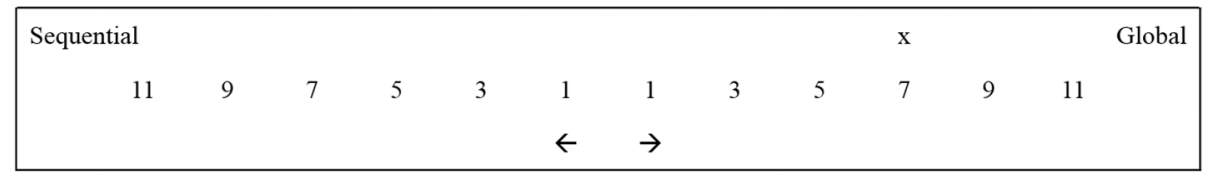

Figure 2. Sample of output received upon completion of ILS. Example Learner shows a balanced active / reflective preference (indicated by score of 1 for active), a moderate intuitive preference (score of 7), a balanced visual/verbal preference (score of 3 for verbal), and a moderate global preference (score of 7).

It is important to keep in mind that learning styles are not absolute characteristics, but merely preferences. ${ }^{5}$ Thus, they are a tool for better understanding how our students' learning and problem solving strategies, and how we may work to expand the ways in which they work with information. ${ }^{5}$ In previous work with learning styles and performance, Kaminski et al. found that students with the predominant learning styles (using the Kolb model) in the population (i.e., students with the learning styles most common to their cohort) had higher performance. ${ }^{11}$ Specifically, they received a higher proportion of As and Bs. ${ }^{11}$ This work supports our hypothesis that we will see differences in performance based on student learning style.

\section{Objective}

We began this study with the aim to determine whether differences in learning style could be observed, identified, and quantified through evaluation of student performance, self-efficacy, problem solving strategies, and attitudes on biased tasks. We define a biased task as a problem (in our study, an exam problem) that exploits specific learning styles in presentation or solution. These tasks are part of the normal course progression, and we do not have any influence in task selection. At this stage, we are interested in evaluating the course (taught by different instructors for different sections/terms) as it is. Thus, the study is designed to have no impact on the course content or evaluation, and minimal impact on the course experience.

Study Design 
Our study is designed to evaluate the correlations between student learning styles, performance, self-efficacy, perceptions/attitudes, and problem solving strategies in the context of the material balances course. The study uses two instruments: 1) the ILS and 2) a series of custom surveys.

The ILS is used to categorize student learning style preferences. As described, the ILS categorizes individuals in the four dimensions of the Felder-Silverman learning styles model as "strong" or "moderate" with respect to one of the opposing preferences, or "balanced" within the dimension. For our study, we look at each dimension separately in correlations with performance, self-efficacy, perceptions/attitudes, and problem solving strategies as we believe that this will allow us to understand if one dimension is more influential, and, if so, in what respect(s).

The second study instrument, surveys, are typically Likert-type questions (on a scale from 1 to 5, strongly disagree to strongly agree, respectively), with some multiple choice, true / false, and occasionally a short open response question. Questions are designed to evaluate student selfefficacy with respect to specific problems and concepts, attitudes, and problem-solving strategies.

The surveys are administered after completion of exams, and focus on a specific exam problem (problem of interest). Prior to each exam, we receive the problems from the instructor and categorize the learning styles exploited in problem presentation and solution. For example, a problem that is presented as a process flow diagram in which students are asked to calculate mass fraction at a specific point in the process would be categorized as "visual presentation" and "sensing solution" since it is presented as a diagram and the solution is numerical.

After the students complete the post-exam survey and exams are graded, we examine student responses for the problem of interest. This allows us a first-hand opportunity to observe problem solving strategies beyond the self-reporting in the surveys. After the graded exams are returned to the students, we may administer a post-return-of-exam survey based on interesting observations from the exam responses. Here, we strive to evaluate whether there is a change in self-efficacy that may correlate with performance (i.e., whether students who initially reported low self-efficacy with respect to the problem but received high marks had an increase in selfefficacy, or vice versa), and whether or not students now understand the problem solution even if they were incorrect on the exam. Examples of questions that may appear in the post-exam or post-return-of-exam survey are shown in Table 2.

Table 2. Sample of questions from survey. Surveys are typically 10-12 questions, and customized for the exam and problem of interest, and also may consider concepts that have been covered in class to date.

For the following questions, think back to the exam you just took (insert date). Specifically, remember as much as you can about Problem $\mathrm{X}$ (short problem descriptor). Please answer the following questions about Problem $X$, the exam, and the course in general.

\begin{tabular}{|l|l|l|l|l|l|}
\hline I Strongly Disagree $2=$ Disagree $3=$ Neutral 4= Agree $5=$ Strongly Agree \\
\hline Problem X was easy to understand. & 1 & 2 & 3 & 4 & 5 \\
\hline I am confident in my solution for problem X. & & & & & \\
\hline I began solving problem X by drawing a process flow diagram. & & & & & \\
\hline I am more comfortable solving numerical problems. & & & & & \\
\hline I prefer problems that I can solve by following a set of ordered steps. & & & & & \\
\hline
\end{tabular}


Results—Learning Styles and Student Performance

Previous studies have shown that engineers tend to be more inclined towards active, sensing, visual, and sequential learning styles. While in each dimension $50 \%$ of the students in our population were categorized as balanced, among students that did have a strong or moderate preference, active, sensing, visual, and sequential were the predominant preferences, which is consistent with the literature. The learning styles profile of the students by dimension for each semester of the study (Spring 2013 and Spring 2014) are shown in Figure 3. Note that each semester is an aggregate report of the profiles for students in two different sections with separate instructors.
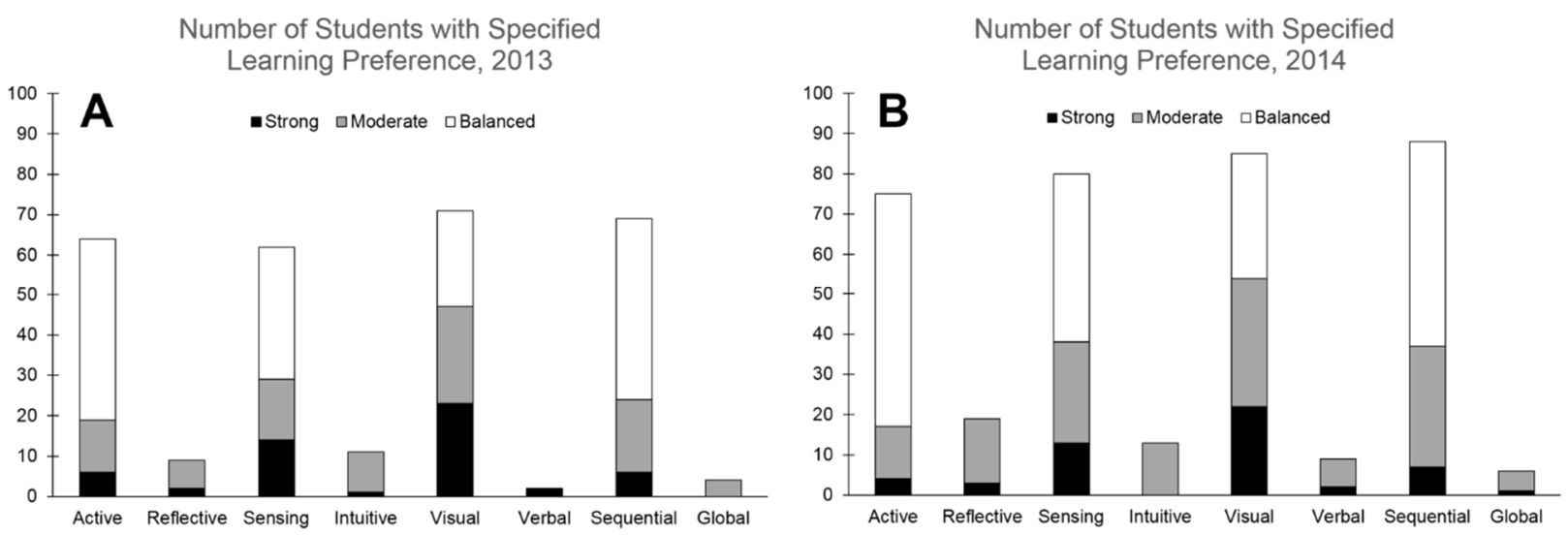

Figure 3. Learning styles profiles for (A) Spring 2013 and (B) Spring 2014 material balances students. Among students with a preference, active, sensing, visual, and sequential are consistently predominant in the population, except in Spring 2014 where there is a nearly equal number of active and reflective students.

In three particular instances, we observed a statistically significant difference $(\alpha=0.05)$ in student performance on an exam problem with respect to learning style. These instances occurred in the sensing/intuitive dimension (intuitors had lower scores), visual/verbal dimension (verbal learners had lower scores), and the sequential/global dimension (sequential learners had higher scores). The respective problems were categorized as sensing solution, visual solution, and sequential solution, thus, these results are not surprising. Figure 4 provides further details about performance in the dimension of interest for these three instances. (We do not share the specific problems here, as the faculty may reuse them from one year to another on exams.) 


\begin{tabular}{|c|c|c|c|c|}
\hline \multirow{4}{*}{$\begin{array}{l}\text { Instance } 1 \\
\text { Sensing/Intuitive - } \\
\text { intuitors had lower } \\
\text { scores }\end{array}$} & Learning Style & Score & $\%$ & \multirow{4}{*}{$\begin{array}{l}\text { Exam Average: } 86 \% \\
\text { Problem Average: } 90 \%\end{array}$} \\
\hline & Sensing & 2.9 & 97 & \\
\hline & Intuitive & 2.2 & 73 & \\
\hline & Balanced & 2.8 & 93 & \\
\hline \multirow{4}{*}{$\begin{array}{l}\text { Instance } 2 \\
\text { Visual/Verbal - } \\
\text { verbal students } \\
\text { had poorer } \\
\text { performance }\end{array}$} & Learning Style & Score & $\%$ & \multirow{4}{*}{$\begin{array}{l}\text { Exam Average: } 52 \% \\
\text { Problem Average: } 69 \%\end{array}$} \\
\hline & Visual & 13.8 & 69 & \\
\hline & Verbal & 6.7 & 34 & \\
\hline & Balanced & 13.8 & 69 & \\
\hline \multirow{4}{*}{$\begin{array}{l}\text { Instance 3: } \\
\text { Sequential/Global - } \\
\text { sequential learners } \\
\text { performed better }\end{array}$} & Learning Style & Score & $\%$ & \multirow{4}{*}{$\begin{array}{l}\text { Exam Average: } 60 \% \\
\text { Problem Average: } 71 \%\end{array}$} \\
\hline & Sequential & 51.1 & 90 & \\
\hline & Global & 40.1 & 70 & \\
\hline & Balanced & 26.5 & 46 & \\
\hline
\end{tabular}

Figure 4. Summary of three instances (exam problems) where a statistically significant difference $(\alpha=0.05)$ in student performance was observed with student learning style.

As the low performance (34\%) of the verbal students in the second instance does not affect the problem average (69\%, same as the visual and balanced students' average scores), it can be deduced that there are not many verbal students. Indeed, verbal students are underrepresented in the population, however, the difference in their performance from visual and balanced peers is so large that it is statistically significant despite the small sample size. It is interesting to note that for the problem that showed a significant difference in student performance in the sequential/global dimension, balanced students performed the worst. This contradicts our general hypothesis that students who are balanced in any dimension will be inherently better equipped to solve any type of problem. We theorize that this may be a result of balanced students having a greater degree of difficulty in focusing on problem solution as they switch back and forth between sequential and global thinking. Further observation of balanced students' problem solving strategies and closer inspection of their exam responses is required to test this new hypothesis.

Observations of student problem solving strategies and self-efficacy revealed interesting general themes and some correlations with learning styles. Within the sensing/intuitive dimension, students seemed to have low self-awareness of preferences. When presented with the statement "I prefer problems with a numerical solution," students of all learning style preferences reported high agreement. However, when asked about a specific problem in which part (a) was a numerical (sensing) solution and part (b) a conceptual (intuitive) solution, intuitors reported disagreement with a statement expressing preference for problems similar to part (a) over part (b). That is, all students reported preferring numerical problems in general, however, on a specific problem with numerical and conceptual components intuitors reported favoring the conceptual portion. This suggests that the students may not have a deep understanding of their own preferences and the types of problems they are exposed to.

All students reported low comfort levels with making assumptions, however, global students reported being slightly more comfortable than their peers. Global students may have fewer 
reservations for making assumptions because they are able to understand a problem beyond the linear sequence of the solution. This may allow them to feel more comfortable with assumptions in contrast to sequential peers who may feel stuck at a step where an assumption is required.

A closer examination of overall course performance and learning style revealed an interesting trend consistent in both semesters. In each semester and section, several different trends existed when comparing student learning styles profiles between those whose performance was in the upper quartile of their class, lower quartile, and the class. However, sequential learners were consistently overrepresented among students scoring in the upper quartile. These results are summarized in Figure 5. As the final scores of students in the separate sections were not significantly different, the two sections within each semester are shown in aggregate.
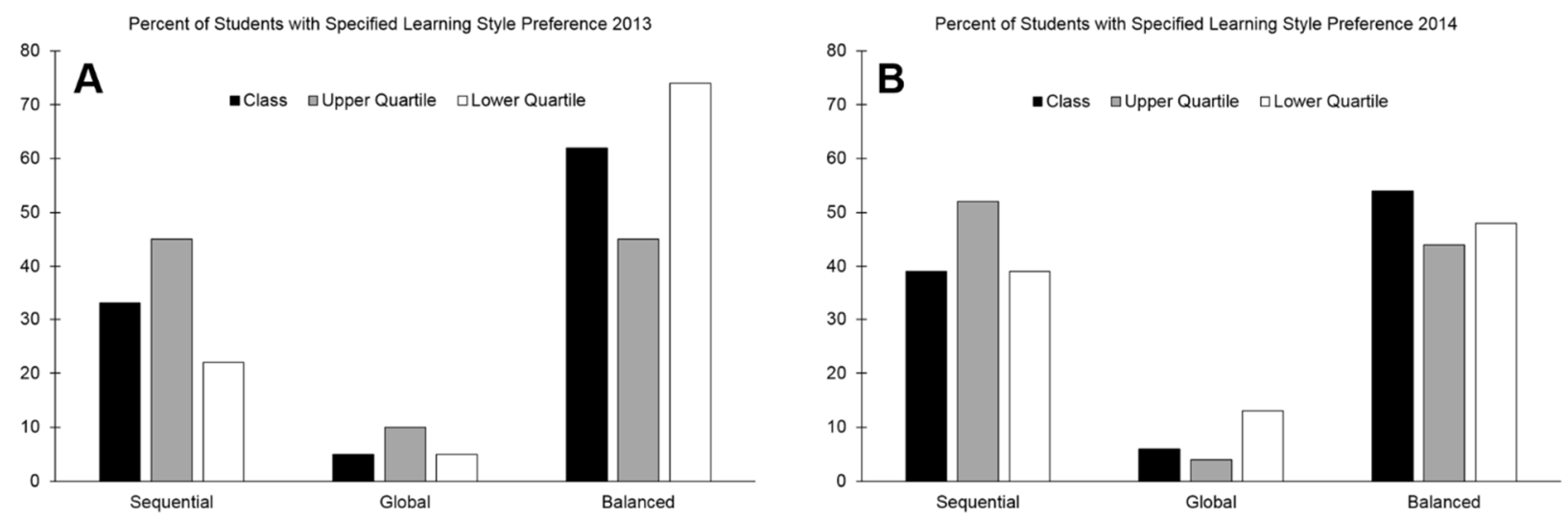

Figure 5. Percentage of students in the class, upper quartile of performance, and lower quartile of performance with respect to the sequential/global dimension in (A) Spring 2013 and (B) Spring 2014. Sequential students are consistently overrepresented in the upper quartile.

Results-Teaching/Evaluation Styles and Student Performance

While categorizing problem types on exams, we noticed a large difference in the types of problems generated by different instructors. Spring 2014 provided a semester in which the contrast was very extreme, and we were prompted to more closely investigate the two sections offered in that semester.

One section, in which we will refer to the instructor as Faculty A, consisted of exam questions that were largely verbal and almost entirely sequential and numerical. Faculty B's exams consisted of problems that engaged each preference of the sensing/intuitive, visual/verbal, and sequential/global dimensions. Both faculty designed their courses and exams intending for the class average to be roughly $80 \%$. Faculty A accomplished this, with the final grades in their section having an average of $82 \%$ prior to any adjustments. Faculty B's section, on the other hand, had an average of $56 \%$. These former grades were scaled up by approximately $25 \%$ before submission, masking the difference in student performance in the two sections when examining the final (adjusted) grades. The difference between the unadjusted final scores in the two sections was statistically significant $(\alpha=0.05)$. This generates new inquiries into how we approach instruction and evaluation in material balances, and what best practices may be. It is arguable that Faculty A has the correct method for student success when measured by performance, but 
we believe that Faculty B's varied problem types better represent the desire to develop our students into more versatile problem solvers and critical thinkers.

\section{Current Work}

We are interested in further investigating the effects of different faculty instruction on the material balances course. At the end of the Spring 2015 semester, we will be administering a concept inventory to both sections of the course. This will be the first time the students from different sections (with different instructors) will be given the same problems to complete. We believe that any differences in student performance on the concept inventory between the two sections will underscore differences in instruction that will allow us to better define course improvements and ensure that all students matriculate from material balances with a strong understanding of the core concepts.

Additionally, we will be giving the same concept inventory to students in our senior design course. We are interested in whether any concepts appear to be better retained, and if there are observable differences in student performance on the concept inventory that correlate with whom the student took material balances earlier in their undergraduate curriculum. If trends are present that suggest correlations between concept retention and instructor, we can use this information to begin identifying the most effective components of each instructor's approach to material balances and leverage these for an improved course design.

\section{Future Work}

We would like to continue investigating the impact of material balances instructor on overall chemical engineering student experience. We are particularly interested in student attitudes and subsequent performance. To accomplish this, we will continue to track a single cohort of students from material balances through the remainder of their career in the chemical engineering program. We will keep track of student retention, subsequent courses and respective instructors, as well as performance, attitudes, and external experiences such as research or internships. We also are in the planning stages of a more homogeneous course model for material balances. The revised course model will focus on exposing students to problems that engage the full spectrum of learning styles. As learning styles describe the cognitive processes involved in information gathering and problem solving, we believe it is important to teach our engineering students to become comfortable with problems of all styles. We are interested in tracking any differences in student performance, experiences, and retention among students before and after the new course model is implemented. This information will provide us with more sound data regarding the influence that material balances may have on students' experiences in chemical engineering and provide a foundation from which to continue improving our course design and developing our full curriculum.

\section{Desired Outcomes and Impact}

We are investigating student factors for success in material balances in an effort to develop improved course materials and a better curriculum. We believe that as the first course in chemical engineering, material balances both provides the foundational knowledge needed to succeed as a chemical engineer and greatly influences student attitudes towards chemical engineering. By better understanding how our methods of instruction may be influencing the students' performance and comprehension, we will be able to develop better materials that both 
suit our students' needs and challenge them to become more versatile thinkers. We hope to develop a more homogeneous structure for the course, to ensure that each student receives an equivalent experience and foundation. This structure includes ensuring that students are evaluated on problems that engage all learning styles, allowing them to expand how they perceive and process information, and thus become better problem solvers.

Bibliography

1 Pashler, H., McDaniel, M., Rohrer, D. \& Bjork, R. Learning Styles: Concepts and Evidence. Psychological Science in the Public Interest 9, 105-119, doi:10.1111/j.1539-6053.2009.01038.x (2008).

2 Rohrer, D. \& Pashler, H. Learning styles: where's the evidence? Medical Education 46, 634-635, doi:10.1111/j.1365-2923.2012.04273.x (2012).

3 Felder, R. M. \& Silverman, L. K. Learning and Teaching Styles in Engineering Education. Engr Education 78, 674-681 (1988).

4 Kolb, D. A. Experiential learning : experience as the source of learning and development. (Prentice-Hall, 1984).

5 Felder, R. M. \& Spurlin, J. Applications, Reliability and Validity of the Index of Learning Styles. Int. J. Engng Ed 21, 103-112 (2005).

6 Martin, E. \& Paredes, P. in First International Workshop on Adaptive Hypermedia and Collaborative Webbased Systems. 188-198.

7 Cook, D. A., Gelula, M. H., Dpuras, D. M. \& Schwartz, A. Instructional methods and cognitive and learning styles in web-based learning: report of two randomised trials. . Medical Education 41, 897-905 (2007).

8 Litzinger, T. A., Lee, S. H., Wise, J. C. \& Felder, R. M. A Psychometric Study of the Index of Learning Styles@. Journal of Engineering Education 96, 309-319, doi:10.1002/j.2168-9830.2007.tb00941.x (2007).

9 Dziedzic, M., de Oliveira, F. B., Janissek, P. R. \& Dziedzic, R. M. in Frontiers in Education Conference, 2013 IEEE. 973-978 (IEEE).

10 Soloman, B. A. \& Felder, R. M. Index of Learning Styles Questionnaire.

11 Kaminski, D. A., Theroux, P. J., Lister, B. C. \& Gabriele, G. A. in American Society for Engineering Education Annual Conference \& Exposition (Portland, OR, 2005). 